\title{
Regulação Assistencial no Recife: possibilidades e limites na promoção do acesso'
}

\section{Assistance Regulatory in Recife: possibilities and limits in promoting access}

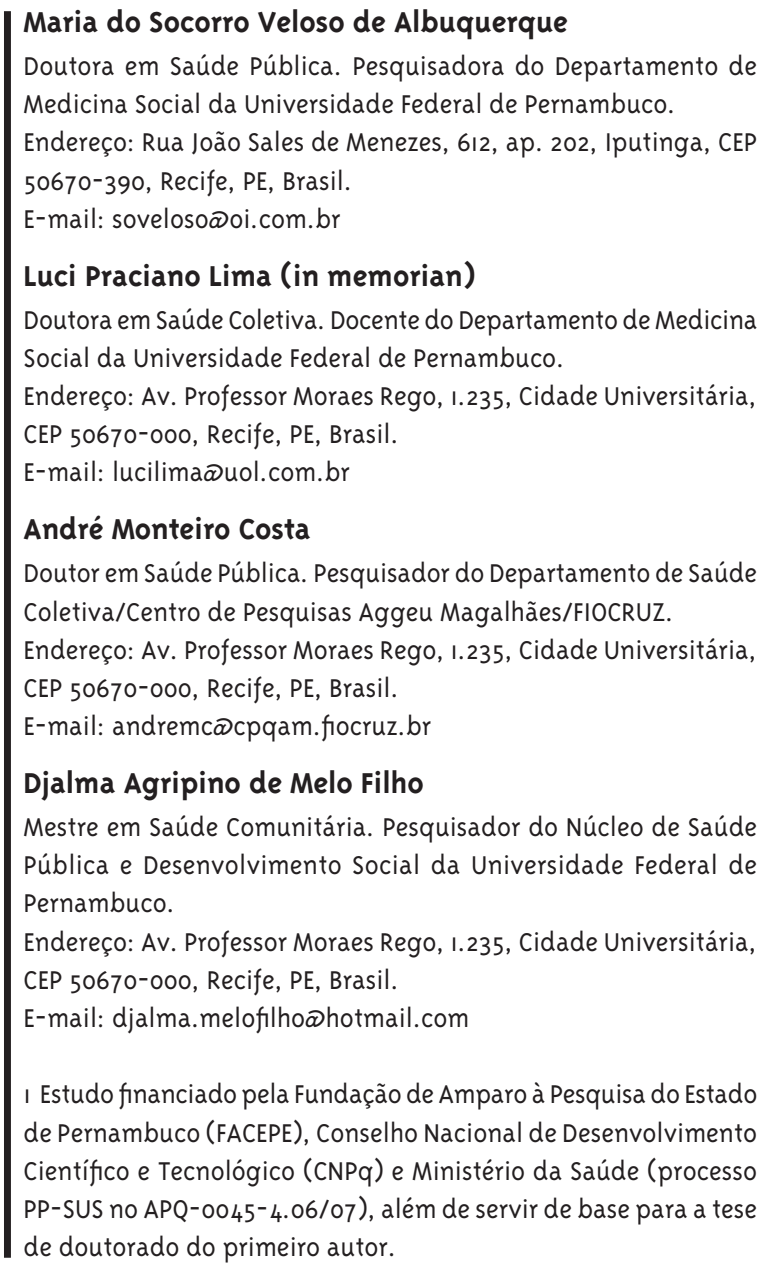

I Estudo financiado pela Fundação de Amparo à Pesquisa do Estado de Pernambuco (FACEPE), Conselho Nacional de Desenvolvimento Científico e Tecnológico (CNPq) e Ministério da Saúde (processo PP-SUS no APQ-0045-4.06/07), além de servir de base para a tese de doutorado do primeiro autor.

\section{Resumo}

A pesquisa analisou o desenvolvimento da regulação assistencial na perspectiva do acesso equânime e integral na Gestão Municipal de Saúde do Recife entre 2001 e 2008. Trata-se de um estudo de caso que teve como sujeitos os gestores e os gerentes da Secretaria de Saúde do Recife. Utilizou-se a análise de conteúdo, na tipologia temática, a partir dos conceitos de triângulo de governo, acessibilidade e rede. Verificou-se que, embora o município tenha implantado arranjos organizacionais de regulação, não incorporou os serviços especializados próprios nem analisou a capacidade potencial desses serviços. A Central de Regulação de Consultas e Exames Especializados absorveu apenas 9,5\% dos procedimentos de média complexidade sob gestão municipal. Outrossim, pouco investiu na ampliação da resolubilidade da atenção básica, mantendo uma possível demanda artificial por serviços especializados. A perspectiva de maior acessibilidade organizacional, pela regulação assistencial, restringiu-se à "adequação" da demanda à oferta da rede complementar SUS/ Recife. Essa oferta, por vezes, foi determinada pelos interesses do próprio setor privado, e a regulação implementada pela gestão municipal teve reduzido poder de definição. A atuação centralizadora da gestão estadual de saúde dificultou a conformação de um complexo regulador compartilhado entre esferas de gestão. Conclui-se que a regulação assistencial, na esfera dos municípios, dificilmente promoverá acesso equânime e integral enquanto atuar somente sobre uma parcela dos serviços sob gestão municipal, intervir sem a formação de redes de atenção regionais, sem pactos efetivos entre entes públicos pela continuidade do cuidado e agir sem subordinar os interesses privados às necessidades assistenciais da população.

Palavras-chave: Acesso aos Serviços de Saúde; Planejamento em Saúde; Regulação e Fiscalização em Saúde. 


\section{Abstract}

The research analyzed the evolution of a service of regulation of care at the Municipal Health Management in Recife, between 2001 to 2008 , from the point of view of access with equity and integrality. A case study was conducted, having the managers from Municipal Health Department of Recife as its subjects. Content analysis was used in a thematic typology, taking as basis the concepts of government triangle, accessibility and network. It was seen that although the municipality implemented organizational arrangements for care regulation, it has neither invested in the regulation of its own specialized services, nor analyzed the potential capacity of these services. The Consultation and Specialized Exams Regulation Service absorbed only 9.5\% of the procedures of medium complexity under municipal management. Moreover, little was invested in the expansion of the solvability of primary care, which contributed to keep a possibly artificial demand for specialized services. The possibility of greater organizational accessibility through the regulation of care was reduced to a process of organizing the existing demand to the capability of supply of SUS' supplementary (private) network in Recife. In some cases, this was defined by the interests of the very private sector, over which the regulation implemented by the municipal administration had reduced power of definition. The centralizing action of the Municipal Health Department hindered the creation of a shared regulatory complex between different levels of management. It is concluded that the regulation of care in the sphere of the municipalities can hardly promote full and equal access if it acts only over the services under municipal management, if it does not form regional networks of care and agreements between public entities for continued care and if it acts without subordinating private interests to the welfare needs of the population.

Keywords: Access to Health Services; Health Planning; Regulation and Supervision in Health.

\section{Introdução}

Com a criação do Sistema Único de Saúde (SUS), houve uma ampliação de ações e serviços ofertados, principalmente pelos municípios; contudo, a obtenção de uma rede de cuidados equânimes e integrais permanece como um propósito a ser alcançado pelo sistema. Ainda persistem acentuadas desigualdades no acesso, sobretudo no que se refere à distribuição dos recursos e oportunidades de utilização dos serviços de saúde entre regiões, Estados, Municípios e grupos sociais (Noronha e col., 2008; Travassos e Castro, 2008; Viana e col., 2003).

Nos últimos anos, tem ocorrido um processo de incorporação institucional de alguns instrumentos de gestão, pelos quais se busca a garantia do acesso e a melhoria na utilização dos serviços do SUS pelos usuários, destacando-se nesse cenário a regulação assistencial (Ferreira e col., 2010; Evangelista e col., 2008; Baduy e col., 2011). No entanto, de forma geral, observa-se uma escassez de mecanismos que assegurem uma efetiva conexão entre a oferta de serviços e a demanda, o que tem contribuído para a manutenção da baixa eficácia do sistema brasileiro de saúde.

A regulação é um conceito polissêmico, originário da teoria dos sistemas e da biologia, e estende-se ao âmbito da economia no qual se defende a intervenção do Estado nas chamadas falhas de mercado. As reflexões sobre esse instrumento de gestão ganham estatuto teórico no contexto da crise do regime fordista ${ }^{2}$ e têm como um de seus principais expoentes teóricos o economista francês Michel Aglietta. $\mathrm{Na}$ abordagem regulacionista, o capitalismo é tido como um sistema instável, sujeito a crises cíclicas. Nesse contexto, portanto, a regulação aparece como "o conjunto de mecanismos e de instituições que permitem a acumulação capitalista funcionar durante períodos relativamente estáveis" (Aglietta, 1979, p. 4). A criação de um aparato regulatório, uma vez aceito pelos agentes econômicos, tenderia a agir de forma anticíclica. Assim, a principal preocupação

\footnotetext{
2 Segundo Teixeira (1998), o fordismo é o regime de acumulação intensiva, hegemônico, pós Segunda Guerra Mundial, com consumo em massa e produção direcionada basicamente ao mercado interno. Seu modelo de regulação caracterizava-se principalmente pela busca da estabilidade nas relações de trabalho (por meio de convenções coletivas) com a instituição do Welfare State e pela importância do Estado na regulação econômica. Regime que, em meados dos anos 1960, entra em crise de acumulação.
} 
da escola de regulação é encontrar novas formas de retirar a economia da crise ${ }^{3}$ e mediar a relação entre Estado e mercado.

No Brasil, no que diz respeito ao setor saúde, a noção de regulação também está associada à relação entre Estado e mercado, pelo fato de o sistema de saúde ser composto por dois subsistemas, o público e o privado. Verifica-se que, mesmo no âmbito do subsistema público, o prestador privado foi privilegiado historicamente na compra de serviços (Santos e col., 2008; Bahia, 2005). Assim, o modelo regulatório direciona-se ora às ações de acesso dos usuários aos serviços de saúde, aos atos de regulamentar e elaborar regras do subsistema público, ora às chamadas falhas do mercado de saúde do subsistema privado. No contexto do subsistema privado, pela forte participação desse setor no mercado de provisão de serviços, foi criada a Agência Nacional de Saúde Suplementar (Brasil, 200o). Segundo dados da Pesquisa Nacional por Amostra de Domicílios (PNAD) de 2008, 49,2 milhões de brasileiros utilizam, de forma simultânea, o SUS e a saúde suplementar (IBGE, 2010).

Em outra perspectiva, Magalhães Jr. (2006), Figueras e colaboradores (2002), Oliveira e Elias (2011) assinalam que a regulação vai além da regulamentação de mercado, pois mantém correspondência com o desempenho dos sistemas públicos de saúde. Nesse caso, a regulação assume a função de reitoria dos sistemas de saúde e intervém no processo de definição de políticas e de regras para os sistemas de saúde.

Os resultados esperados com a introdução da regulação em saúde poderiam ser verificados em múltiplas dimensões. Em relação aos recursos humanos e equipamentos, sua distribuição poderia ser melhorada, assim como as iniquidades do acesso. Sobre as instituições de ensino, haveria influência no sentido de formar profissionais em consonância com as necessidades de saúde. Efeitos também são esperados na relação entre os interesses dos prestadores e os objetivos do sistema e na adequação do cuidado em todos os níveis do próprio sistema. Além disso, a interferência na relação público-privado poderá promover a equidade no uso dos serviços (Oliveira e Elias, 2011).

Segundo Santos e Merhy (2006), a regulação é inerente a qualquer sistema de saúde e se desenvolve em um cenário de disputas e interesses conflitantes. No Brasil, desde a implementação do SUS até meados dos anos 1990, mediante a edição das diversas Normas Operacionais Básicas (NOBs), o sistema de regulação concentrava-se nas atividades de controle e avaliações financeira e contábil. A temática da regulação assistencial somente surge com a criação da Norma Operacional da Saúde (NOAS) 2001/2002 (Brasil, 2002a), embora com uma concepção limitada de resolubilidade de rede, dirigida apenas à média e à alta complexidade, não incluindo, portanto, a atenção básica como componente central do processo. Além do mais, a regulação assistencial apresentava-se desarticulada das ações de controle e avaliação.

Com o Pacto pela Saúde, em seu componente Pacto de Gestão, define-se a regulação assistencial como o "conjunto de relações, saberes, tecnologias e ações que intermedeiam a demanda dos usuários por serviços de saúde e o acesso a estes" (Brasil, 2006a). Nele, a regulação assistencial configura-se como elemento da regulação da atenção e articula-se com as atividades de contratação, controle, avaliação e auditoria assistencial no âmbito dos prestadores públicos e privados.

De acordo com Mendonça e colaboradores (2006), quando a regulação assistencial está fundada nas diretrizes de universalidade, integralidade e equidade, tanto ela poderá expandir quanto reduzir determinada oferta, já que seu objetivo central será subsidiar o redimensionamento da oferta e responder de forma adequada aos problemas clínicos e à satisfação dos usuários. Os autores destacam que a regulação assistencial vai além da utilização de protocolos, cotas assistenciais, normas, uso de computadores e softwares ou controle financeiro, pois implica articulações na esfera técnico-política e no âmbito do cuidado.

Assim, compreende-se que o desenvolvimento

3 De acordo com Braga (2003), apesar de a teoria da regulação partir de alguns conceitos marxistas, a abordagem regulacionista se distancia desta linha teórica, sobretudo porque, conforme o marxismo, as crises do capitalismo não redundam em sua superação. 
de projetos de regulação assistencial, como arranjo de gestão para produção de cuidado equânime e integral, desenrola-se num cenário de conflitos decorrentes de interesses público-privados que permeiam o sistema. Além disso, verificam-se disputas intergovernamentais entre os municípios e entre eles e os governos estaduais na organização de sistema de saúde. 0 cenário de competições, conforme ressalta Mendes (2009), tem dificultado os pactos interfederativos, com repercussão na constituição de complexos regulatórios a serem compartilhados entre esferas de governo.

No presente estudo, parte-se do pressuposto de que a consolidação de um sistema de regulação assistencial, que promova acesso com equidade e integralidade aos serviços de saúde, no âmbito de uma gestão municipal, dependerá dos investimentos municipais na capacidade de governo e na governabilidade. Considera-se que os fatores capacidade de governo e governabilidade ampliam as possibilidades da gestão municipal para melhor apreender e satisfazer as necessidades de serviços da população e para subordinar os interesses privados, que monopolizam o sistema de saúde, a tais necessidades. Além disso, ampliam a capacidade do município de influir na formação dos complexos regulatórios assistenciais compartilhados entre entes federados para garantir a continuidade do cuidado.

Em face do exposto, analisou-se o desenvolvimento do processo de regulação assistencial, na perspectiva do acesso equânime e integral, na gestão municipal da saúde no Recife entre 2001 e 2008.

\section{Métodos}

A pesquisa foi realizada no município do Recife, no período que compreende as duas gestões do Governo João Paulo (2001-2004 e 2005-2008). A primeira delas caracterizou-se pela expansão de cobertura da atenção básica e a segunda, pela busca de estratégias de qualificação do acesso a outros níveis de atenção. Na ocasião do estudo, o município encontrava-se em gestão plena do sistema pela NOB 96, sem exercer direção ou comando único sobre a rede de serviços de saúde situada em seu território, como previam a NOAS 2002 (Brasil, 2002a) e o Pacto pela Saúde (Brasil, 20o6a). Segundo esses instru- mentos normativos, um único gestor responde por toda a rede assistencial na sua área de abrangência, conduz a negociação com os prestadores e assume o comando da política de saúde em seu território.

Trata-se de um estudo de caso no qual se integrou uma ampla variedade de evidências, tais como documentos e entrevistas, conforme sugerido por Yin (2005). Como fontes de informação, foram utilizados os planos municipais de saúde de 2002-2005 e de 2006-2009, os dados do Sistema de Informação Ambulatorial (SIA-SUS), do Sistema de Informação Hospitalar (SIH-SUS) e do Cadastro Nacional de Estabelecimentos de Saúde (CNES). Além disso, foram realizadas entrevistas semiestruturadas com duração máxima de uma hora cada e com um roteiro que continha as seguintes questões: conteúdo do projeto de regulação assistencial do Recife, definição dos fluxos e programação assistencial, funcionamento da Central de Regulação de Consultas e Exames Especializados e relação entre os gestores municipal e estadual de saúde na promoção do acesso. Para compor o elenco de sujeitos da pesquisa, foram selecionados três ex-secretários de saúde, identificados como gestores A, B, C; três diretores da regulação da esfera central da Secretaria Municipal de Saúde (SMS), denominados como gestores D, E, $\mathrm{F}$ e três gerentes distritais, chamados de gerentes distritais A, B, C.

Utilizou-se a análise de conteúdo, de modelo temático, por meio da condensação de significados (Kvale, 1996) tanto nas entrevistas quanto nos documentos institucionais. A análise compreendeu descrição, sistematização, comparação e interpretação dos aspectos considerados significativos em todo o material coletado, articulando-se o referencial teórico e os achados analíticos construídos na pesquisa. Cada entrevistado recebeu uma codificação com o intuito de garantir o anonimato.

A análise foi mediada pelos conceitos de triângulo de governo de Matus (Matus, 1993), acesso/acessibilidade (Donabedian, 2003; 1973) e rede (Cecílio, 2001; Mattos, 2001; Mendes, 2009; Castells, 2000; Inojosa, 2008; 1999).

Para Matus (1993), todo ator que planeja não tem assegurada sua capacidade de controlar a realidade, pois dependerá da ação de outros atores, como também da destreza e habilidades necessárias para 
executar o projeto. $\mathrm{O}$ autor sintetiza o ambiente da gestão por meio de três vértices de um triângulo com interação entre si. Em um deles, está o projeto de governo, que contém o conteúdo propositivo do plano. Em outro, ancora-se a governabilidade, que se refere à possibilidade de ação e ao controle dos efeitos desta ação pelo governante que demonstra o potencial de articulação com os agentes envolvidos nos âmbitos internos e externos. Finalmente, no terceiro, aparece a capacidade de governo enquanto exercício de liderança, mediada por experiência e conhecimento, habilidades, métodos e técnicas que o governante e sua equipe possuem para conduzir o processo, dados a governabilidade do sistema e o compromisso do projeto de governo.

Segundo Travassos e Martins (2004), acesso é um conceito complexo muitas vezes empregado de forma imprecisa na sua relação com o uso de serviços de saúde. Seu significado varia entre autores e conjunturas. Neste estudo, adotou-se o conceito proposto por Donabedian (2003; 1973), que é abordado como acessibilidade e abrange duas dimensões: a geográfica e a sócio-organizacional. A primeira refere-se à distância e ao tempo de locomoção dos usuários para chegarem aos serviços, incluindo os custos da viagem, dentre outros. A segunda, a todas as características da oferta que facilitem ou dificultem a capacidade das pessoas no uso dos serviços. Conforme Donabedian (2003; 1973), os serviços devem ser oportunos e contínuos para atenderem à real demanda e serem capazes de assegurar o acesso a outros níveis de atenção.

Por fim, destaca-se a questão do funcionamento dos serviços em rede, enquanto possibilidade de articulação entre níveis de complexidade da assistência com vistas à continuidade do cuidado. Esse aspecto diz respeito a um dos sentidos da integralidade do qual tratam autores como Cecílio (2001), Mattos (2001) e Mendes (2009). É importante, porém, ressaltar que o conceito de rede tanto está relacionado à forma de organização do sistema de saúde quanto à relação entre os atores sociais (Castells, 2000; Inojosa, 1999; Hartz e Contandriopoulos, 2004).

De acordo com Castells (2000), para integrar uma rede, enquanto uma estrutura dinâmica, é imprescindível que seus integrantes estabeleçam uma ligação entre si, compartilhem valores e objetivos comuns, decodificáveis em um processo de comunicação. Nessa direção, Inojosa (1999) assinala dois tipos de rede: a primeira delas, a rede subordinada, é formada de entes que são parte de uma organização ou sistema, com interdependência de objetivos, mas nessa configuração só há um lócus de poder. A outra, a rede autônoma, é constituída de entes autônomos, com objetivos específicos próprios que se articulam a partir de uma ideia-força mobilizadora; é aberta, trabalha por pactuação, e o controle pode mudar de lócus. Portanto, nesse arranjo, o poder é fragmentado e o conflito é inexorável.

A pesquisa foi aprovada pelo Comitê de Ética em Pesquisa (CEP) do Centro de Pesquisa Aggeu Magalhães/FIOCRUZ (parecer nํ21/2009).

\section{Resultados e Discussão}

\section{A regulação assistencial dos serviços de saúde sob gestão municipal}

A cidade do Recife caracteriza-se por comportar em seu território uma das maiores redes públicas de serviços de saúde do Brasil. Em 2008, segundo dados do CNES, existiam 45 unidades hospitalares vinculadas ao SUS das quais $45 \%$ eram públicas estatais e 55\% privadas e filantrópicas. Já a rede ambulatorial possuía 235 unidades, entre as quais $85 \%$ eram públicas estatais. Do ponto de vista da gestão da rede de serviços de saúde, embora o município tenha sido habilitado em gestão plena do sistema desde a NOB/96 (Secretaria de Saúde do Recife, 2002), não se garantiu a direção única. Em 2008, a rede sob gestão municipal era composta por 22 unidades tradicionais de atenção básica e 118 Unidades de Saúde da Família (USFs), 18 Centros de Atenção Psicossocial (CAPS), 11 policlínicas, seis hospitais de média complexidade, três maternidades, 25 clínicas especializadas e 24 unidades de apoio diagnóstico e exames.

Em um cenário de disponibilidade de recursos oportunizado pelo Ministério da Saúde para organização de estruturas municipais de regulação, sobretudo pelas prerrogativas do pacto de gestão (Brasil, 2006), o município criou a Diretoria Geral de Regulação do Sistema de Saúde do Recife em 2006 com o propósito de ordenar o acesso aos serviços de saúde com equidade e integralidade (Secretaria de Saúde do Recife, 2006). 
Para os três ex-secretários de saúde entrevistados, a regulação assistencial foi concebida como mecanismo de acessibilidade organizacional e expressou o intento da gestão em estabelecer um canal de comunicação e de conciliação entre as unidades assistenciais para promover o acesso dos usuários aos serviços de saúde, conforme depoimentos:

[...] A regulação assistencial veio para melhorar a comunicação entre as unidades, para que o usuário saia, no caso de necessidade, da unidade básica com sua consulta especializada garantida. [...] Esperamos com ela também melhorar a atuação das nossas unidades básicas e do sistema de saúde do Recife como um todo (Gestor C).

[...] Nessa gestão ampliamos a rede básica e especializada, mas começamos a perceber que não tínhamos assegurado o acesso, não havia referenciamento efetivo à atenção especializada. Entendemos a regulação como instrumento para garantir o acesso, ela deve atuar para que a população não ande e nem perca tanto tempo nas suas caminhadas para ter acesso a um serviço. Acima de tudo, ela otimiza a organização do serviço, porque não fica aquele tipo de estrutura em que a população chega hoje e não é atendida, ou é encaminhada, mas não tem a garantia do atendimento porque não tem nada acordado entre os serviços (Gestor B).

\section{[...] O município agregou aos serviços já existentes} de controle avaliação, ações para adequar a oferta à demanda, por meio da discussão e pactuação dos fluxos assistenciais de referência e contrarreferência, implantação da central de regulação de consultas exames, ações de auditoria, não apenas no sentido do controle, mas também como ação de qualificação dos serviços, principalmente a partir de 2006, com a concepção de regulação advinda com o pacto (Gestor A).

Nessa perspectiva, os gestores da Secretaria Municipal esperavam superar o restrito papel desempenhado pela Diretoria de Programação, Controle e Avaliação na primeira gestão (2001-2004). Na época, as atividades concentraram-se no credenciamento e acompanhamento contábil e financeiro dos prestadores da rede complementar, conforme relato a seguir:
A atuação dessa diretoria concentrava-se no credenciamento e acompanhamento contábil e financeiro dos prestadores da rede complementar, principalmente, no processo de correção das faturas apresentadas (Gestor D).

Atenta-se para o fato de que a estrutura de regulação até então existente espelhava-se em uma lógica de trabalho similar àquela desenvolvida pelo antigo Instituto Nacional de Assistência Médica e Previdência Social (INAMPS). A esse respeito, Santos e Merhy (2006) e Inojosa (1996) apontam que a transferência das atividades de regulação para Estados e Municípios não implicou, necessariamente, uma mudança de abordagem que suplantasse a visão do controle burocrático adotada na relação com aos prestadores privados. As atividades de controle e avaliação, em grande parte dos municípios, ainda não se traduziram num processo de avaliação de serviços com impacto no planejamento e nas práticas assistenciais e de regulação assistencial.

Com relação ao projeto de governo, concebido por Matus (1993), como conteúdo propositivo, há evidências de que a gestão municipal tinha como intencionalidade a promoção do acesso equânime e integral aos serviços de saúde por meio de um processo de regulação assistencial. Não obstante, os achados demonstram as dificuldades na consolidação desse projeto.

A SMS do Recife privilegiou, na implantação de seu projeto de regulação assistencial, a reestruturação dos fluxos assistenciais, a partir de um processo de discussão com os profissionais das unidades básicas e especializadas. Na rede própria, foi possível redefinir os fluxos, considerando o conceito de acessibilidade geográfica, quanto à distância e ao tempo de locomoção dos usuários para chegarem aos serviços, conforme conceitua Donabedian (1973). Apesar disso, no que se refere à rede complementar ao SUS/Recife, a SMS teve reduzida governabilidade para negociar com os principais representantes do setor privado, no sentido de descentralizar serviços, alterar a concentração deles em alguns bairros e/ ou substituir prestadores. O relato a seguir é representativo da percepção da maioria dos gestores (ex-secretários e diretores da regulação): 
A gente tentou respeitar e definir, para cada Unidade de Saúde da Família/USF, quais seriam as unidades prestadoras do território mais adequadas na questão da proximidade geográfica. [...] a gente queria privilegiar o território, colocando unidades prestadoras mais próximas da unidade solicitante. Mas, nem sempre aquelas unidades prestadoras da rede complementar tinham o desenho ideal, adequado e próximo das USF. Como também não foi possivel substituir prestadores (Gestor E).

Verifica-se, então, uma forte influência dos interesses dos próprios prestadores privados na localização dos serviços de saúde, que os concentraram em alguns bairros. Morais (2002) constata que, no Recife, os serviços do subsistema privado estão estrategicamente situados em bairros onde a riqueza urbana está mais concentrada. Para a autora, o subsistema privado de serviços de saúde corresponde a uma diversidade de rede de serviços de saúde, organizada em função da logicidade da oferta e direcionada à obtenção de lucro no âmbito do Sistema Único de Saúde.

Para enfrentar os limites de uma programação assistencial ainda muito centrada em série histórica de produção e/ou nos parâmetros da Portaria GM 1.101 (Brasil, 2002b), a SMS do Recife instituiu, a partir de 2007, alguns critérios de ajuste na programação assistencial especializada. Segundo um dos gestores entrevistados, buscava-se atender equitativamente às diferentes necessidades assistenciais demandadas pela atenção básica em cada distrito sanitário. Para tanto, utilizou-se uma combinação de critérios:

[...] demanda reprimida (referida pelos profissionais eusuários); perfil epidemiológico da área de atuação de cada unidade básica; contingente populacional atendido; estratificação de risco de determinados grupos populacionais elou populações residentes em microrregiões com maior dificuldade de acesso à atenção especializada. Com esses critérios, a gente busca adequar a distribuição das cotas para cada unidade básica (Gestor D).

De forma geral, os dados indicam que o processo de regulação praticado pela SMS do Recife, no período em estudo, trouxe mudanças no padrão uniforme de distribuição dos procedimentos especializados.
Por meio de oficinas de programação assistencial, com a participação dos profissionais da atenção básica, buscou-se adequar a programação às necessidades identificadas em cada distrito sanitário. Nesse sentido, observa-se uma aproximação com a concepção de equidade defendida por Jardaniviski e Guimarães (1993), Vieira-da-Silva e Almeida (2009) na qual a distribuição de ações e serviços de saúde deve ser feita para todos, mas em proporção às diferentes necessidades, com critérios distintos de distribuição.

Por outro lado, na avaliação dos três gerentes distritais, a adequação da programação assistencial não permeou a totalidade da rede de serviços sob gestão municipal; prevaleceram em muitos casos os parâmetros instituídos pela Portaria 1.101 com insuficiência de oferta, como exemplificado nos relatos a seguir:

[...] em muitas situações não foi possível aplicar critérios de ajuste da programação assistencial, face à indisponibilidade de informações em saúde em determinadas regiões do município e/ou pela própria limitação imposta pelo teto financeiro (Gerente Distrital C).

[...] Em todos os distritos sanitários houve insuficiência de oferta. O que pode significar inadequação desses parâmetros (da Portaria 1.101) à realidade local (Gerente Distrital B).

Não obstante, quando indagados sobre as causas da permanência dessa modalidade de programação, tanto os gestores quanto os gerentes distritais foram unânimes em assinalar a fragilidade dos sistemas de informações em saúde no município para subsidiar a incorporação de novos parâmetros assistenciais no processo da programação assistencial em sua totalidade.

Nesse sentido, Santos e Merhy (2006) consideram que o avanço do processo de regulação da assistência impõe a integração dos vários subsistemas em um Sistema Nacional de Informação em Saúde, composto dos mesmos padrões de informação, tabelas, cadastros, entrada de dados, identificações comuns. Isso possibilitaria cruzamentos, extração de indicadores e constituiria, de fato, um instrumento para as ações da regulação assistencial, avaliação e programação assistencial. 
No tocante à implantação e funcionamento da central de regulação ${ }^{4}$, tomando-se como referência o conceito de acesso concebido por Donabedian (1973), pode-se constatar um consenso entre os distintos relatos dos entrevistados quanto à concepção de regulação assistencial como uma das estratégias necessárias para garantir uma melhor acessibilidade organizacional aos serviços de saúde. Os depoimentos adiante seguem essa direção:

O usuário vivenciava uma verdadeira via crucis para ter acesso à atenção especializada, mesmo dentro dos serviços sob gestão municipal (Gestor D).

O fato de o usuário não precisar mais comprar uma vaga na fila, e nem dormir na porta da unidade especializada..., pra mim é um ganho de cidadania sem precedentes. Simplesmente você saber que a marcação da sua consulta e dos seus exames é uma responsabilidade da secretaria de saúde. Ela é que deve garantir seu acesso, no mínimo às unidades que estão sob gestão do município, é um avanço para o Sistema Municipal. Ela é uma ferramenta para garantir a continuidade do cuidado (Gestor F).

Apesar disso, os gerentes distritais ressaltaram os limites da central nos dois anos de sua implantação: "A central apenas incorporou os serviços do setor complementar, na rede própria continua cada distrito fazendo seu agendamento" (Gerente distrital A). Segundo informações da Diretoria de Regulação Municipal, em 2008, a central municipal regulou 28 mil cotas mensais, distribuídas em 18 especialidades médicas e seis procedimentos, correspondendo a 9,5\% dos procedimentos de média complexidade sob gestão do município. Dessa forma, a rede pública municipal não foi regulada pela central, mesmo produzindo a maior parte da oferta ambulatorial em termos de exames e consultas $(65 \%$ em 2001 e $60 \%$ em 2008, segundo informações do SIA-SUS).

A esse respeito concorda-se com Ferreira e colaboradores (2010) sobre a importância da inserção de toda a oferta própria e complementar numa central de regulação para se viabilizar o gerenciamento e o controle da oferta e para obter o acompanhamento da execução dos procedimentos em tempo satisfatório. Sem esse mecanismo, a garantia da melhor e oportuna resposta aos problemas dos usuários, premissa da implantação das centrais de regulação, fica essencialmente comprometida.

Quanto a esse tema, verifica-se que a Central de Regulação de Consultas e Exames da rede municipal do Recife funcionou com reduzida capacidade técnica e política sobre o conjunto dos serviços de saúde, distanciando-se da possibilidade de oferecer "a melhor alternativa assistencial". Na avaliação de um dos gestores da regulação entrevistado, essa situação foi motivada pelo fato de a regulação não ter ficado tão encaixada na prioridade de governo como deveria ser, em termos de investimentos técnicos, financeiros e políticos (Gestor E).

Outro tema importante na discussão da regulação assistencial, como ressaltam Spedo e colaboradores (2010), é a resolubilidade da atenção básica. A relação entre atenção básica e a média complexidade é um dos fatores condicionantes desse parâmetro, eles enfatizam a necessidade de adoção de estratégias de comunicação contínua entre todos os atores envolvidos. No caso do Recife, os gestores entrevistados, por unanimidade, aproximam-se desta compreensão, conforme demonstrado no relato a seguir: [...] a regulação começa na unidade básica de saúde, com a melhoria na identificação de necessidades, com a qualificação dos encaminhamentos, com mecanismos de diálogo entre os profissionais da atenção básica com as unidades de referência (Gestor B).

Segundo os gerentes distritais, no entanto, os esforços da SMS na prática diária concentraram-se na implantação de protocolo de acesso à atenção especializada sem um processo sistemático de discussão no cotidiano dos serviços, conforme se pode observar no conteúdo dos relatos a seguir:

[...] Não basta ter cotas e ficha de encaminhamento, fluxo ou protocolo, também é preciso ter espaço de diálogo entre as equipes envolvidas, ficamos nos protocolos. [...] Regular é formar rede, não é um serviço de saúde ao léu, é formar rede de suporte à atenção básica, discutindo processo de trabalho e

4 A central de regulação municipal tem o objetivo de regular o acesso a consultas e exames nas áreas consideradas estratégicas pela gestão municipal (Secretaria de Saúde do Recife, 20o6). 
a relação entre as unidades. [...] se teve dificuldade em manter uma discussão permanente com a rede de serviços sobre a missão do que é complexo regulatório e o papel de cada unidade na regulação de acesso (Gerente distrital A).

Temos problemas nos encaminhamentos da atenção básica, de coisas que poderiam ser resolvidas na própria atenção básica, mas que se encaminham à atenção especializada. [...] Não juntamos regulação assistencial com educação permanente (Gerente distrital B).

[...] a gente não discutiu de forma mais sistemática o que é regulação, o que é processo de regulação dentro dos distritos sanitários. [...] não temos pessoas que pensem a regulação dentro dos distritos. [...] não promovemos de forma contínua e sistemática uma interlocução entre os profissionais nos vários pontos da rede (Gerente distrital C).

No âmbito do processo de comunicação entre as unidades de saúde, tomando-se como referência o conceito de rede em Castells (200o) e Inojosa (1999), os achados indicam que o processo instituído pela regulação no Recife não possibilitou aos atores sociais, integrantes dos serviços sob gestão municipal, o compartilhamento de valores e objetivos comuns, decodificáveis em um processo de comunicação, condição necessária para se ter um processo de regulação assistencial compartilhado entre todos os atores envolvidos.

Segundo Baduy e colaboradores (2011) e Campos (2006), os métodos de padronização, como protocolos com mudanças nas práticas da clínica, não podem estar desarticulados da constituição de espaços democráticos de pactuação entre os diversos atores envolvidos. Os autores referem-se, ainda, à necessidade de ampliar a resolubilidade da atenção básica, mediante um processo de discussão contínua e sistematizada das práticas.

No Recife, dos seis distritos sanitários, apenas um deles (Distrito Sanitário VI) apresentou relatos nesse sentido, ao programar, desde 2004, um projeto de regulação assistencial que, embora restrito à sua área de abrangência e à população local, buscou o diálogo entre as equipes das unidades de saúde e destas com os profissionais da atenção especializada, visando à melhoria do acesso. Assim, percebe-se um investimento na concepção de rede ressaltada por autores como Castells (200o) e Inojosa (2008; 1999).

No que diz respeito à atuação específica da central municipal, as descobertas instigam a reflexão sobre a possibilidade de a regulação não ter superado uma programação assistencial centrada numa possível demanda artificial. Segundo dados da central de consultas e exames, as cinco especialidades, em 2008, com maior demanda reprimida 5 (oftalmologia, ortopedia, otorrinolaringologia, cardiologia, urologia) são as mesmas com maiores percentuais de absenteísmo nas consultas.

De acordo com Mendonça e colaboradores (2006), com o SUS, houve aumento de cobertura da atenção básica e uma inadequação da oferta de média e alta complexidade. Nesse sentido, tanto pode ocorrer uma demanda artificial por serviços de maior complexidade com encaminhamentos desnecessários quanto escassez de oferta em algumas áreas, devido a baixo investimento ou indisponibilidade de capacidade instalada.

As descobertas apontam que a regulação, no período em estudo, não investiu na formulação de um diagnóstico consistente sobre a capacidade instalada dos serviços próprios e sobre o percentual efetivo de utilização desses serviços. Desse modo, o município distanciou-se do princípio de esgotamento da capacidade dos serviços próprios para posterior definição de compra no setor complementar, conforme definido pela Portaria GM/ MS n 3.277 (Brasil, 20o6b). De acordo com uma parcela dos gestores municipais entrevistados, esse processo sofreu influência da atuação política dos prestadores privados, conforme se pode observar nos relatos transcritos a seguir:

Há dez anos, tudo entrava por influência, a gente "herdou" esses serviços privados e uma dificuldade de mexer nisso muito grande, politicamente, com muitos bombardeios. [...] A gente pode ser refém, como se tem sido de algumas instituições, pela força

5 A demanda reprimida refere-se à fila de espera da atenção especializada gerenciada pela central (rede complementar), ou seja, não inclui a rede própria. 
política que elas têm, pelos próprios serviços que prestaram dentro de Pernambuco e pela própria postura interna da Prefeitura. A rede meio que ficou refém de algumas situações (Gestor F).

Sóagora, em 2009, éque estamos mapeando nossas unidades, a capacidade instalada dos serviços próprios sob gestão municipal, o que a gente tem que investir em tecnologia, estrutura e pessoal, definir perfil e missão de cada uma, de acordo com o modelo que a gente quer. Fazendo isso, a gente já elimina várias formas de compra (Gestor $\mathrm{A}$ ).

No que se refere à relação público-privada, tanto os gestores quanto os gerentes distritais entrevistados destacaram o processo de despolitização da política de regulação assistencial no município e os limites desta quando restrita ao corpo técnico da diretoria de regulação, com incipiente participação do Conselho Municipal de Saúde. Pode-se concluir que as atividades de controle assistencial, inerentes a um processo de regulação, restringiram-se ao âmbito dos "anéis burocráticos" (Cardoso, 1973), sem a participação da sociedade civil organizada, representada no Conselho Municipal de Saúde/CMS:

[...] O processo de regulação assistencial envolve uma compra a partir das necessidades dos usuários, mas isso envolve muitos interesses... $\varepsilon$ o conselho não tem pautado isso. Na minha avaliação, a diretoria de regulação tem reduzido poder para mexer nisso (Gerente distrital A).

[...] no acompanhamento da compra foi prevista a participação do usuário, de seu representante no conselho, mas foi o segmento que mais apresentou dificuldades em participar das reuniões (Gestor D).

Como salienta Stotz (2006), a temática da regulação da atenção vem se consolidando no SUS à margem das instâncias de controle social. Tem ocupado a pauta de discussão das comissões intergestoras tripartite e bipartite, principal esfera decisória do SUS na atualidade, ao mesmo tempo em que tem se distanciado da esfera de atuação dos conselhos. A esse respeito, Bahia (2005) considera que a regulação das interfaces entre o público e o privado no sistema de saúde no Brasil não adquiriu o estatuto de tema da agenda de debates. A autora ressalta ainda que continuam pouco visíveis as articulações e contraposições entre as políticas voltadas a maximizar a equidade e aquelas voltadas à viabilização dos processos de acumulação de bens e serviços privados de saúde.

\section{A relação entre esferas de governo na promoção do acesso}

De acordo com as evidências encontradas no estudo, a gestão de saúde do Recife responsabilizou-se pela totalidade da rede de atenção básica no território municipal e por apenas $34,6 \%$ da totalidade dos procedimentos de média complexidade. Não participou da regulação de nenhum dos procedimentos de alta complexidade, realizados pelos serviços sob gestão estadual, reflexo do processo de duplo comando. Achados semelhantes foram destacados por Pinto e colaboradores (2010) ao assinalarem que, embora a concentração da maior parte dos serviços de média e alta complexidade - tanto públicos quanto privados vinculados ao SUS - esteja nos municípios de grande porte - particularmente nas capitais de Estado -, não se têm consolidado estratégias efetivas para viabilizar uma direção única. Assim, os aportes assinalados contextualizam as possibilidades e limites de um projeto de regulação municipal em promover acesso com equidade e integralidade sem comando único.

Durante os oito anos analisados, não se configuraram as condições políticas e técnicas necessárias para o município assumir o comando único, tanto sob a égide da NOAS/2002 (Brasil, 2002a) quanto pelo pacto de gestão (Brasil, 2006a). Em 2008, segundo dados do CNES, dos 45 estabelecimentos de saúde de internação situados no território do Recife vinculados ao SUS, 15 unidades (33,3\%) tinham duplo comando, destas 12 eram públicas (80\%).

Tomando-se como referência o conceito de rede de Castells (2000) e a tipologia de rede criada por Inojosa (1999), os dados apontam para a existência de uma rede subordinada em que um dos entes se institui enquanto lócus de poder. No relato de um dos gerentes distritais, observa-se a ausência da participação do município na cogestão de leitos, que são disponibilizados sem obedecerem ao critério de acessibilidade geográfica. Para grande parte dos gestores municipais entrevistados, o Estado de Pernambuco caracteriza-se, dentre outros aspectos, 
pela posição tanto centralizadora quanto concentradora de recursos no governo do Estado, o que tem dificultado a conformação de redes regionalizadas e de um complexo regulatório compartilhado. Os fragmentos dos relatos a seguir retratam esse cenário:

Tem-se no Estado uma frágil regionalização da assistência, já que os instrumentos, como plano diretor regionalizado, programação pactuada integrada e complexo regulatório não têm retratado um efetivo processo de negociação com os municípios (Gestor C).

[...] Apesar de grande parte da rede de serviços de saúde sob gestão estadual estar situada no território municipal, a população recifense não tem tido acesso referenciado. [...] O governo do Estado ainda não tem um processo de regulação na média complexidade, ele tem ali uma regulação de leitos, que não é cogerida com o Recife. No nível ambulatorial existe uma marcação por telefone em que o próprio usuário é quem liga. Não se tem uma PPI (Programação Pactuada e Integrada), PDR(Plano Diretor Regionalizado), PDI(Plano Diretor de Investimentos) e um complexo regulatório de fato pactuado. O governo estadual detém 70\% da média complexidade e $100 \%$ da alta [...] o Estado tem uma preocupação de implantar serviços, não de funcionamento em rede, não tem concepção de rede (Gestor $\mathrm{B}$ ).

É importante frisar, porém, que essa não é uma particularidade do Estado de Pernambuco. Em estudo realizado na região de Campinas (SP), Assis e colaboradores (2009) enfatizam que, apesar da implantação da regionalização no Estado de São Paulo, o governo estadual ainda compete com os municípios na execução direta dos serviços. Nesse sentido, acaba por não concentrar esforços no que deveria ser a sua atribuição mais importante: a coordenação, a avaliação e a indução de políticas através de pactuações e financiamentos específicos.

As descobertas, ainda, apontam para dificuldades no acesso no que diz respeito à continuidade dos cuidados subsequentes, quando se toma por referência a concepção adotada por Cecílio (2001) e Donabedian (2003;1973). Situação assinalada por um dos gerentes distritais entrevistados:

Nossas mulheres vão parir em outros municípios, quando temos suficiência de leitos de baixo e alto risco. [...] Na política de saúde da mulher, a gente disponibilizou tudo o que a política nacional estabelece em relação às mulheres. Mas, a gente sente falta de ter o complemento dessa estrutura numa unidade de maior complexidade, para garantir a continuidade do cuidado (Gerente distrital C).

Por outro lado, observa-se que o segundo período de governo foi marcado pelo predomínio da racionalidade política sobre a técnica no processo decisório da gestão municipal. No que se refere à gestão municipal como um todo, optou-se pelo não acirramento da disputa política com o Governo do Estado. Na saúde, isso se expressa na retirada da agenda do dirigente (Matus, 1993) de temas que marcaram a primeira gestão, tais como: comando único e cogestão de leitos ${ }^{6}$. 0 relato que segue sintetiza a compreensão que os gestores da regulação e os gerentes distritais entrevistados tiveram a esse respeito:

Esmoreceu a meta pela implementação do comando único; não se investiu mais na articulação para cogestão de leitos hospitalares, tanto eletivos, quanto de urgência e emergência; não tivemos espaço de diálogo efetivo com o gestor estadual para obter acesso regulado de consultas e exames para população recifense nos serviços sob gestão estadual (Gestor E).

Na segunda gestão sentimos que permaneceríamos com duplo comando. O governo estadual não queria discutir comando único e a gente não teve força para ampliar essa discussão, então... (Gerente Distrital A).

\section{Considerações Finais}

Verifica-se, a partir dos meios empregados, que a gestão municipal do Recife, no período estudado, embora tenha se empenhado na construção de um sistema de regulação assistencial, não conseguiu

6 Questões que permearam os planos municipais 2002-2005 (Secretaria de Saúde do Recife, 2002) e 2006-2009 (Secretaria de Saúde do Recife, 2005) e a pauta da $6^{\text {a }}$ Conferência Municipal de Saúde. 
promover o acesso com equidade e integralidade dos serviços de saúde, conforme os propósitos iniciais de governo. Os resultados apontam para um distanciamento ou não articulação entre os vértices do triângulo de governo de Matus (1993). Constata-se, portanto, que não basta desenhar bem um projeto, uma vez que todo ator que planeja não tem assegurada sua capacidade de controlar a realidade, pois depende da ação de outros e do investimento em destrezas e habilidades para executar o seu projeto.

No caso do Recife, tornou-se insustentável a premissa de que, com a regulação assistencial, poderse-ia disponibilizar a alternativa assistencial mais adequada à necessidade do cidadão. 0 município não avançou o suficiente na regulação dos serviços especializados próprios, na produção do conhecimento da capacidade potencial desses serviços e na sua operacionalização. No que se refere à atenção básica, não houve qualificação sistemática do processo de trabalho, no sentido da ampliação dos níveis de resolubilidade e redução da produção de uma procura artificial por serviços especializados. Dessa forma, a possibilidade de maior acessibilidade organizacional, por meio da regulação assistencial, ficou reduzida a um processo de "adequação" da demanda à oferta da rede complementar SUS Recife que, em alguns casos, foi definida pelos próprios interesses do setor privado, quando a regulação logrou reduzido poder de definição.

Considera-se que o processo de regulação assistencial, na esfera dos municípios, dificilmente promoverá acesso com a necessária equidade e integralidade enquanto os gestores municipais de saúde regularem apenas parte dos serviços sob gestão municipal e não atuarem na subordinação dos interesses privados às necessidades assistenciais da população. Outrossim, a não influência desses gestores na formação de redes de atenção regionais e de pactos efetivos entre entes públicos tem repercutido na garantia do acesso. Além disso, a atitude da gestão estadual de saúde, no que se refere à concentração de recursos e serviços, tem dificultado a construção do processo de regionalização e de consolidação de complexos regulatórios compartilhados entre Estado e Municípios.

\section{Referências}

AGLIETTA, M. Regulación y crisis del capitalismo. México, DF: Siglo Ventiuno, 1979.

ASSIS, E. et al. Regionalização e novos rumos para o SUS: a experiência de um colegiado regional. Saúde e Sociedade, São Paulo, v. 18, p. 17-21, 2009. Suplemento 1.

BADUY, R. S. et al. A regulação assistencial e a produção do cuidado: um arranjo potente para qualificar a atenção. Cadernos de Saúde Pública, Rio de Janeiro, v. 27, n. 2, p. 295-304, 2011.

BRAGA, R. A nostalgia do fordismo: modernização e crise na teoria da sociedade salarial. São Paulo: Xamã, 2003.

BAHIA, L. Padrões e mudanças no financiamento e regulação do sistema de saúde brasileiro: impactos sobre as relações entre o público e privado. Saúde e Sociedade, São Paulo, v. 14, n. 2, p. 9-30. 2005 .

BRASIL. Lei ํㅜ 9.961, de 28 de janeiro de 2000. Cria a Agência Nacional de Saúde Suplementar - ANS e dá outras providências. Diário Oficial da União, Brasília, DF, 29 jan. 200o. Seção 1, edição extra, p. 5 .

BRASIL. Ministério da Saúde. Portaria nํ373, de 27 de fevereiro de 2002. Norma Operacional da Assistência à Saúde - NOAS-SUS 01/o2: estabelece o processo de regionalização como estratégia de hierarquização dos serviços de saúde. Diário Oficial da União. Brasília, DF, 28 fev. 2002(a). Seção 1, p. 52.

BRASIL. Ministério da Saúde. Portaria GM/MS nํ⒈101, de 12 de junho de 2002. Dispõe sobre parâmetros de cobertura assistencial no âmbito do SUS. Diário Oficial da União, Brasília, DF, 12 jun. 2002(b). Seção 1, v. 139, n. 112, p. 36.

BRASIL. Ministério da Saúde. Portaria nํㅜ 399, de 22 de fevereiro de 2006. Divulga o Pacto pela Saúde 2006 - Consolidação do SUS e aprova as diretrizes operacionais do referido pacto. Diário Oficial da União, Brasília, DF, 23 fev. 2006(a). Seção 1, p. 43-51. 
BRASIL. Ministério da Saúde. Portaria GM/MS no 3.277, de 22 de dezembro de 2006. Dispõe sobre a participação complementar dos serviços privados de assistência à saúde no âmbito do Sistema Único de Saúde. Diário Oficial da União, Brasília, DF, 26 dez. 2006(b). Seção 1, p. 253.

CAMPOS, G. W. S. Clínica e saúde coletiva compartilhadas: teoria Paidéia e reformulação ampliada do trabalho em saúde. In: CAMPOS, G. W. S. et al. (Org.). Tratado de saúde coletiva. São Paulo: Hucitec; Rio de Janeiro: Fiocruz, 2006. p. 53-92.

CARDOSO, F. H. O modelo político brasileiro e outros ensaios. 2. ed. São Paulo: Difusão Européia, 1973.

CASTELLS, M. A sociedade em rede. Rio de Janeiro: Paz e Terra, 2000.

CECÍLIO, L. C. O. As necessidades de saúde como conceito estruturante na luta pela integralidade e eqüidade na atenção em saúde. In: PINHEIRO, R.; MATTOS, R. A. (Org.). Os sentidos da integralidade na atenção e no cuidado à saúde. São Paulo: Hucitec, 2001. p. 113-126.

DONABEDIAN, A. Aspects of medical care administration. Boston: Harvard University, 1973.

DONABEDIAN, A. An introduction to quality assurance in health care. New York: Oxford University, 2003.

EVANGELISTA, P. A.; BARRETO, S. M.; GUERRA, H. L. Central de regulação de leitos do SUS em Belo Horizonte, Minas Gerais, Brasil: avaliação de seu papel pelo estudo das internações por doenças isquêmicas do coração. Cadernos de Saúde Pública, Rio de Janeiro, v. 24, n. 4, p. 767776, 2008.

FERREIRA, J. B. B. et al. O complexo regulador da assistência à saúde na perspectiva de seus sujeitos operadores. Interface: Comunicação, Saúde, Educação, São Paulo, v. 14, n. 33, p. 345-358, 2010.

FIGUERAS, J.; MUSGROVE, P.; CARRIN, G.; DIRÁN, A. Retos para los sistemas sanitários de Latinoamérica: ¿qué puede aprenderse de la experiencia europea? Gaceta Sanitaria, Barcelona, v. 16, n. 1, p. 5-17, 2002.
HARTZ, Z. M. A.; CONTANDRIOPOULOS, A. P. Integralidade da atenção e integração de serviços de saúde: desafios para avaliar a implantação de um sistema "sem muros". Cadernos de Saúde Pública, Rio de Janeiro, v. 20, p. 331-336, 2004. Suplemento 2.

IBGE - INSTITUTO BRASILEIRO DE GEOGRAFIA E ESTATÍSTICA. Pesquisa Nacional por Amostra de Domicílios. Um panorama da saúde no Brasil: acesso e utilização dos serviços de saúde, condições de saúde, fatores de risco e proteção à saúde, 2008. Rio de Janeiro, 2010.

INOJOSA, R. M. Avaliação e controle do SUS: mudam-se as práticas? Cadernos FUNDAP, São Paulo, n. 19, p. 88-97, 1996.

INOJOSA, R. M. Redes de compromisso social. Revista de Administração Pública, Rio de Janeiro, v. 33, n. 5, p. 115-141, 1999.

INOJOSA, R. M. Revisitando Redes. Divulgação em Saúde para Debate, Rio de Janeiro, n. 41, p. 36-46, 2008.

JARDANIVISKI, E.; GUIMARÃES, P. C. V. O desafio da equidade no setor saúde. Revista de Administração de Empresas, Rio de Janeiro, v. 33, n. 3, p. 38-51, 1993.

KVALE, S. Interviews: an introduction to qualitative research interviewing. London: Sage, 1996.

MAGALHÃES JR, H. M. O desafio de construir e regular redes públicas, com integralidade, em sistemas privado-dependentes: a experiência de Belo Horizonte. 2006. Tese (Doutorado em Saúde Coletiva) - Universidade Estadual de Campinas, Campinas, 2006.

MATTOS, R. A. Os sentidos da integralidade: algumas reflexões acerca de valores que merecem ser defendidos. In: PINHEIRO, R.; MATTOS, R. A. (Org.). Os sentidos da integralidade na atenção e no cuidado à saúde. Rio de Janeiro: UERJ: Abrasco, 2001. p. 39-64.

MATUS, C. Política, planejamento e governo.

Brasília, DF: IPEA, 1993. 2 t.

MENDES, E. V. As redes de atenção à saúde. Belo Horizonte: ESP-MG, 2009. 
MENDONÇA, C. S.; REIS, A. T.; MORAES, J. C. (Org.). A política de regulação no Brasil. Brasília, DF: OPAS: MS, 20o6. (Série técnica desenvolvimento de sistemas e serviços de saúde, 12).

MORAIS, H. M. M. Uma análise da assistência médico hospitalar privada: o pólo médico da cidade do Recife na travessia do século XX para o XXI. 2002. Tese (Doutorado em Saúde Coletiva) Universidade Estadual de Campinas, Campinas, 2002.

NORONHA, J. C.; LIMA, L. D.; MACHADO, C. V. O Sistema Único de Saúde - SUS. In: GIOVANELLA, L. et al. (Org.). Políticas e sistema de saúde no Brasil. Rio de Janeiro: Fiocruz, 20o8. p. 435-476. OLIVEIRA, R. R.; ELIAS, P. E. M. Regulação em saúde. In: IBAÑEZ, N.; ELIAS, P. E. M.; D’ÂNGELO SEIXAS, P. H. (Org.). Política e gestão pública em saúde. São Paulo: Hucitec Cealag, 2011. p. 204-218.

PINTO, N. R. S.; SPEDO, S. M.; TANAKA, O. Y. (Im) possibilidades de implementar uma direção única no SUS em município de grande porte: o caso de São Paulo, Brasil. Saúde e Sociedade, São Paulo, v. 19, n. 3, p. 518-532, 2010.

SANTOS, F. P.; MERHY, E. E. A regulação pública da saúde no Estado brasileiro: uma revisão. Interface: Comunicação, Saúde, Educação, São Paulo, v. 10, n. 19, p. 25-41, 2006.

SANTOS, I. S.; UGÁ, M. A. D.; PORTO, S. M. O mix público-privado no sistema de saúde brasileiro: financiamento, oferta e utilização de serviços de saúde. Ciência e Saúde Coletiva, Rio de Janeiro, v. 13, n. 5, p. 1431-1440, 2008.

SECRETARIA DE SAÚDE DO RECIFE. Plano Municipal de Saúde do Recife: 2002-2005. Recife, 2002.

Recebido em: 16/08/2010

Reapresentado em: 10/10/2011

Aprovado em: 04/09/2012
SECRETARIA DE SAÚDE DO RECIFE. Plano

Municipal de Saúde do Recife: 2006-2009. Recife, 2005.

SECRETARIA DE SAÚDE DO RECIFE. Diretoria Geral de Regulação do Sistema. Relatório de gestão 2006. Recife, 2006.

SPEDO, S. M.; PINTO, N. R. S.; TANAKA, O. Y. O difícil acesso a serviços de média complexidade do SUS: o caso da cidade de São Paulo, Brasil. Physis, Rio de Janeiro, v. 20, n. 3, p. 953-972, 2010.

STOTZ, E. N. Trajetória, limites e desafios do controle social do SUS. Saúde em Debate, Rio de Janeiro, v. 3o, n. 73/74, p. 141-144, 2006.

TEIXEIRA, F. J. S. Modernidade e crise: reestruturação capitalista ou fim do capitalismo? In: TEIXEIRA, F. J. S.; OLIVEIRA, M. A. de (Org.). Neoliberalismo e reestruturação produtiva: as novas determinações do mundo do trabalho. São Paulo: Cortez, 1998. p. 15-74.

TRAVASSOS, C.; CASTRO, M. S. M. Determinantes e desigualdades sociais no acesso e na utilização de serviços de saúde. In: GIOVANELLA, L. et al. (Org.). Políticas e sistema de saúde no Brasil. Rio de Janeiro: Fiocruz, 2008, p. 215-246.

TRAVASSOS, C.; MARTINS, M. Uma revisão sobre os conceitos de acesso e utilização de serviços de saúde. Cadernos de Saúde Pública, Rio de Janeiro, v. 20, p. S19o-S198, 2004. Suplemento 2.

VIANA, A. L.; FAUSTO, M. C. R.; LIMA, L. D. Política de saúde e equidade. São Paulo em Perspectiva.

São Paulo, v. 17, n. 1, p. 58-68, 2003.

VIEIRA-DA-SILVA, L. M.; ALMEIDA, N. F. Equidade em saúde: uma análise crítica de conceitos.

Cadernos de Saúde Pública, Rio de Janeiro, v. 25, p. 217-226, 2009. Suplemento 2.

YIN, R. K. Estudo de caso: planejamento e método. 3. ed. Porto Alegre: Bookman, 2005. 